\title{
Surface Properties of Cement Paste Evaluated by Scanning Probe Microscopy
}

\author{
Yuya Sakai \\ Institute of Industrial Science, The University of Tokyo, Tokyo, Japan \\ Email: ysakai@iis.u-tokyo.ac.jp
}

How to cite this paper: Sakai, Y. (2016) Surface Properties of Cement Paste Evaluated by Scanning Probe Microscopy. Open Journal of Civil Engineering, 6, 643-652.

http://dx.doi.org/10.4236/ojce.2016.64052

Received: September 5, 2016

Accepted: September 26, 2016

Published: September 29, 2016

Copyright $\odot 2016$ by author and Scientific Research Publishing Inc. This work is licensed under the Creative Commons Attribution International License (CC BY 4.0).

http://creativecommons.org/licenses/by/4.0/

\begin{abstract}
The microscopic physical properties of Hardened Cement Paste (HCP) surfaces were evaluated by using Scanning Probe Microscopy (SPM). The cement pastes were cured under a hydrostatic pressure of $400 \mathrm{MPa}$ and the contacting surfaces with a slide glass during the curing were studied. Scanning Electron Microscope (SEM) observation at a magnification of 7000 revealed smooth surfaces with no holes. The surface roughness calculated from the SPM measurement was $4 \mathrm{~nm}$. The surface potential and the frictional force measured by SPM were uniform throughout the measured area $24 \mathrm{~h}$ after the curing. However, spots of low surface potential and stains of low frictional force and low viscoelasticity were observed one month after curing. This change was attributed to the carbonation of hydrates.
\end{abstract}

\section{Keywords}

Cement Paste, Scanning Probe Microscopy, Surface Potential, Frictional Resistance, Viscoelasticity

\section{Introduction}

Many studies focused on the reliable prediction of the extent of chloride ion ingress into concrete. Electrostatic effects from the pore wall become important when chloride ions transfer through small pores into concrete [1]. Because the surface potential of pore walls is difficult to measure directly, these effects have been modeled by using the zeta potential formalism [2] [3]. Zeta potential is generally evaluated by measuring the amount of solution or ions that migrate through the concrete specimen, driven by potential difference. The obtained zeta potentials, however, are average values and their distribution has not been well understood. The understanding of the surface potential distribution is important from the perspective of multi-scale modeling of cement paste matrices. Scanning Probe Microscopy (SPM) is a general term for methods that derive 
information from the physical interaction between a probe and the object being studied [4]. The SPM method allows for the atomic scale investigation of surfaces and can measure the distribution of surface potential, where SPM was applied to study thin films [5] [6], minerals [7] [8] or organic molecules [9]. Some researchers measured the surface geometry of Hardened Cement Paste (HCP) or cementitious material by SPM [10]-[13]. Scanning probe microscopy, however, can only evaluate the surface properties of reasonably smooth surfaces, so the Maximum Heights of the Profile should not exceed a few $\mu \mathrm{m}$. Accordingly, SPM hardly gives reasonable results on objects with rough surfaces or large pores, such as normal concrete or cement paste. In a previous study, triaxial tests were carried out on HCP under confining pressures of $0,30,100$, and $400 \mathrm{MPa}$ [14]. The porosity decreased significantly after the test under $400 \mathrm{MPa}$. In another study, hydrostatic pressure was applied on crushed HCP, which resulted in the plastic deformation of the powder, along with particle adherence [15]. These results show that porosity, which hinders SPM measurement, might be reduced by applying high pressure on cement paste. Therefore, in this study, SPM was applied on HCP cured under high pressure, in order to measure the microscopic distribution of the surface potential. The surface morphology of the samples was evaluated by Scanning Electron Microscopy (SEM) and field emission scanning electron microscopy with energy dispersive X-ray spectroscopy (FE-SEM/EDS).

\section{Experimental}

\subsection{Specimen Preparation}

The water to cement ratio of the HCP studied was 0.25 . Ordinary Portland cement was used and its properties are shown in Table 1. The mixing procedure was based on JIS R 5201; the paste was first mixed for $60 \mathrm{~s}$ at low speed. The mixer was stopped to scrape off cement paste on the side of the mixing bowl and the paddle. Then the paste was mixed for $90 \mathrm{~s}$ at high speed. The mixed cement paste was placed on a cut glass plate $\left(25 \times 20 \times 1.5 \mathrm{~mm}^{3}\right)$. The cement paste and the plate were wrapped in a plastic film and an industrial wiper, and were vacuum packed. The wiper and the film were used for removing excess water and preventing the sticking of cement paste on the wiper, respectively. A hydrostatic pressure of $400 \mathrm{MPa}$ was then applied for 24 or $72 \mathrm{~h}$. After depressurizetion, the samples were taken out from the pack and immersed into acetone for $24 \mathrm{~h}$ to stop the hydration reaction. The prepared samples were approximately 15 mm wide, $30 \mathrm{~mm}$ long, and $3 \mathrm{~mm}$ tall. The samples were kept at $20^{\circ} \mathrm{C}$ and $20 \%$ relative humidity for $24 \mathrm{~h}, 72 \mathrm{~h}$, or 1 month after the acetone immersion and then tested. The conditions for the sample preparation and the tests conducted on the samples are

Table 1. Cement properties.

\begin{tabular}{ccccccc}
\hline \multirow{2}{*}{ Ignition Loss } & \multicolumn{4}{c}{ Chemical property (\%) } & $\begin{array}{c}\text { Density } \\
\mathrm{g} / \mathrm{cm}^{3}\end{array}$ & $\begin{array}{c}\text { Specific surface area } \\
\mathrm{cm}^{2} / \mathrm{g}\end{array}$ \\
\hline 2.00 & $\mathrm{MgO}$ & $\mathrm{SO}_{3}$ & $\mathrm{Na}_{2} \mathrm{O}_{\mathrm{eq}}$ & $\mathrm{Cl}^{-}$ & & 3350 \\
\hline
\end{tabular}


summarized in Table 2. A photograph of the sample after high-pressure curing for $72 \mathrm{~h}$ and acetone immersion is shown in Figure 1.

\subsection{SEM and FE-SEM/EDS}

A $1 \mathrm{~mm}^{3}$, cubic sample was taken from the HCP sample and the surface contacting with a glass plate during the high-pressure curing was studied by SEM. Of the remaining sample, FE-SEM observation and EDS analysis were applied on the surface that was in contact with a glass plate.

\subsection{Scanning Probe Microscopy}

The surface geometry of the samples was measured in dynamic force mode, in which the distance between the probe and the sample was controlled in order to achieve oscillation amplitude. The surface geometry was measured on the same area studied with FE-SEM/EDS. The scanning resolution and scanning frequency were $512 \times 256$ and approximately $0.3 \mathrm{~Hz}$, respectively. Surface potential was calculated based on the feedback potential, by keeping the amplitude of the electrostatic component (due to excitation) zero. A frictional force was derived from the torsional displacement of the cantilever during scanning. The samples were axially vibrated and the flexural oscillation of the cantilever was measured in order to evaluate viscoelasticity. At the current stage, the absolute values obtained using these techniques have no physical meaning, but can only be used for qualitative description. The surface geometries of all samples were

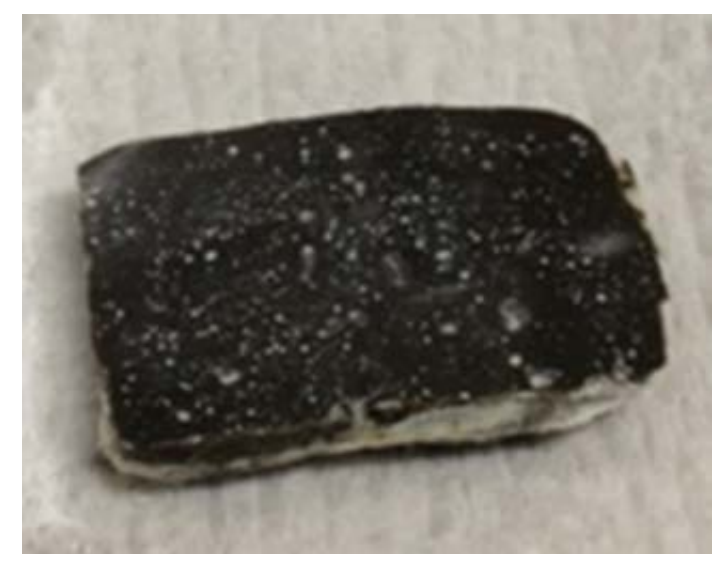

Figure 1. Photograph of press-cured cement paste.

Table 2. Experimental conditions.

\begin{tabular}{|c|c|c|}
\hline $\begin{array}{l}\text { High pressure } \\
\text { curing period }\end{array}$ & $\begin{array}{c}\text { Interval between } \\
\text { immersion and measurement }\end{array}$ & Measurements \\
\hline $72 \mathrm{~h}$ & $72 \mathrm{~h}$ & SEM, SPM(Surface geometry) \\
\hline $24 \mathrm{~h}$ & $24 \mathrm{~h}$ & $\begin{array}{c}\text { FE-SEM/EDS, SPM } \\
\text { (Surface geometry, surface potential and frictional force) }\end{array}$ \\
\hline $24 \mathrm{~h}$ & 1 month & $\begin{array}{l}\text { SPM(Surface geometry, surface potential, } \\
\text { frictional force and viscoelasticity) }\end{array}$ \\
\hline
\end{tabular}


measured; additionally, the frictional force was measured on the sample that was rested for $24 \mathrm{~h}$ between acetone immersion and the test. The frictional force and viscoelasticity of the sample that was rested for a month were measured as well.

\section{Results}

\subsection{SEM and FE-SEM/EDS}

The result of SEM observation of the $1 \mathrm{~mm}^{3}$ cubes is shown in Figure 2. The surface was flat and no holes were seen, although there was some observable surface roughness. The results of FE-SEM are shown in Figure 3-hexagonal hydrates are seen. The elemental mapping obtained by EDS is shown in Figure 4. The analysis was carried out on the area enclosed by the dashed lines in Figure 3. More $\mathrm{Ca}$ and less $\mathrm{Si}$ were detected on the hexagonal hydrates denoted by the letter $\mathrm{A}$ in Figure 3. Fe and $\mathrm{Al}$ were detected in some parts of the rest of the sampled area.

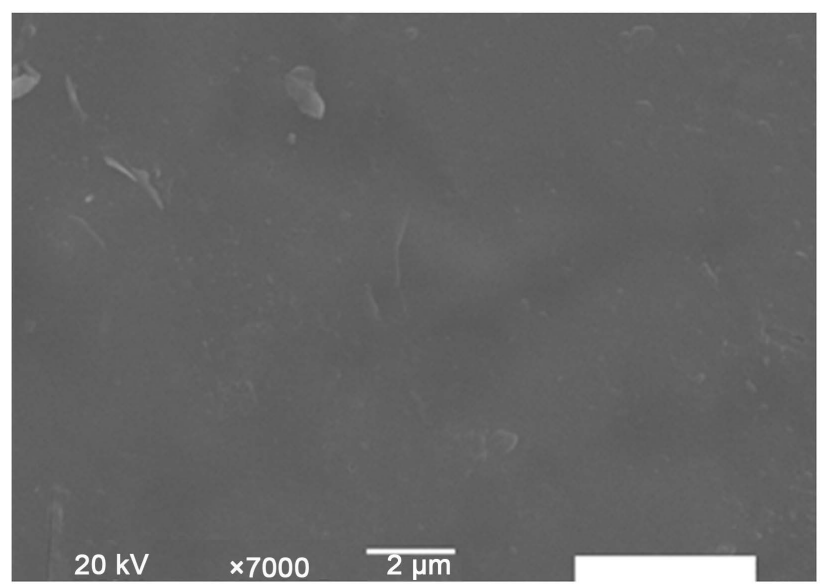

Figure 2. SEM image of press-cured cement paste.

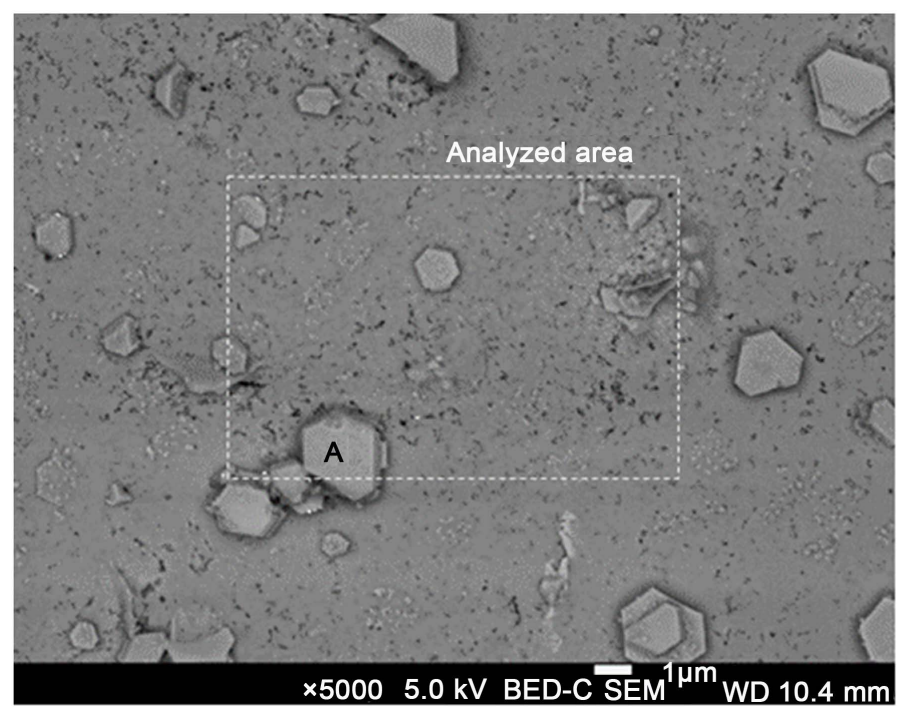

Figure 3. FE-SEM image of cement paste. 


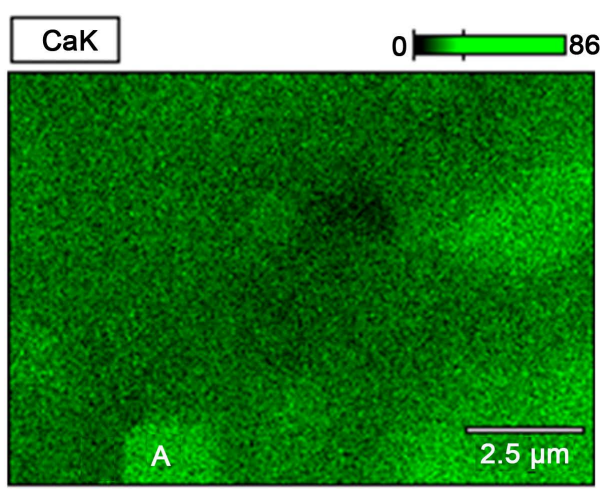

(a)

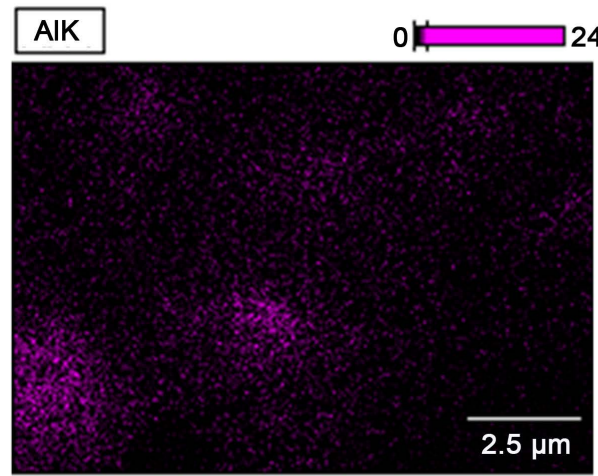

(c)

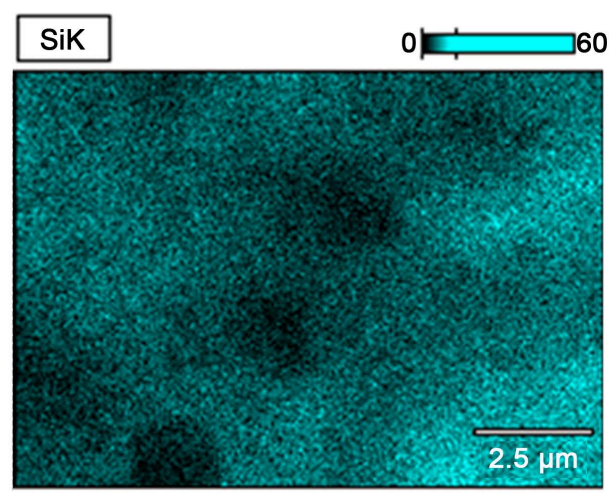

(b)

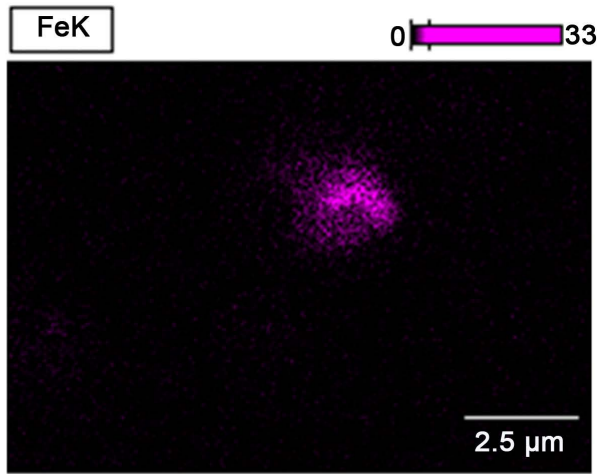

(d)

Figure 4. Distribution of some elements on cement paste. (a) Mapping of Ca; (a) Mapping of Ca; (c) Mapping of Al; (d) Mapping of Fe.

\subsection{Scanning Probe Microscopy}

The surface geometry of HCP, which was cured under high pressure for $72 \mathrm{~h}$ and measured $72 \mathrm{~h}$ after acetone immersion, is shown in Figure 5. Brighter colors indicate more elevated regions. The maximum height difference in Figure 5 was $25 \mathrm{~nm}$ and no holes were observed. The calculated surface roughness (the arithmetic average of the absolute values of the profile height deviations from the mean line) was $4 \mathrm{~nm}$.

The surface properties of the HCP, which was cured under high pressure for $24 \mathrm{~h}$ and measured $24 \mathrm{~h}$ after acetone immersion, are shown in Figure 6. The letter A indicates the same hydrates shown in Figure 4(a). Botryoidal and platy hydrates can be seen on the flat surface in Figure 6(a). The surface potential and frictional force distribution are shown in Figure 6(b) and Figure 6(c), respectively. Brighter colors indicate higher values in both figures. Both properties appeared to be different over the edges of hydrates than in those in flat areas. Surface properties of the HCP, which were measured one month after acetone immersion, are shown in Figure 7 and Figure 8. Frictional force and viscoelasticity were measured in the same area but the surface potential was measured at a different location. There were spots with lower surface potential in Figure $7(\mathrm{~b})$. Lower frictional force and lower viscoelasticity were obtained in distinct patches, as seen in Figure 8. 


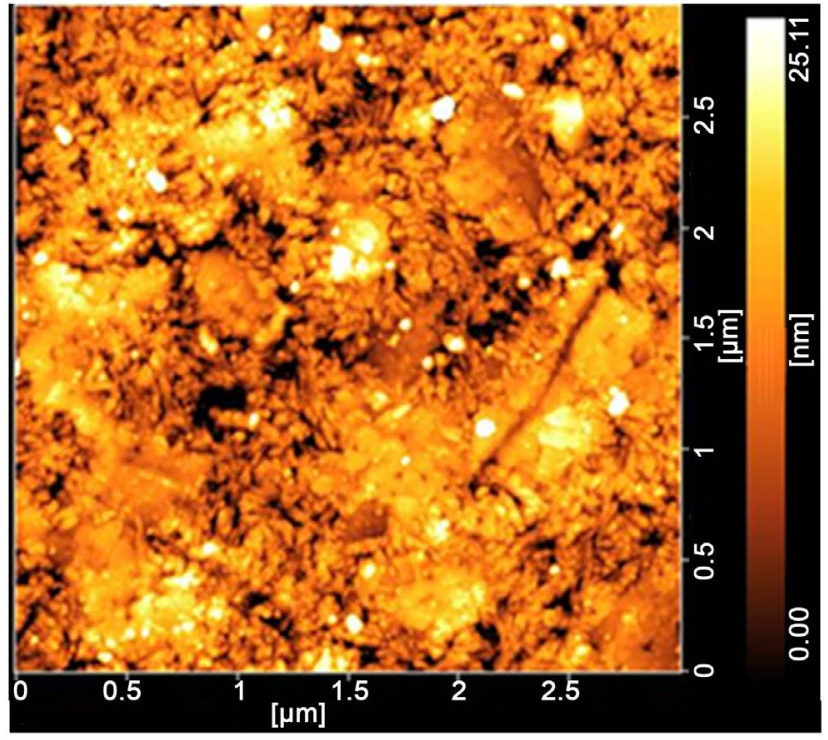

Figure 5. Surface shape scanned by SPM.

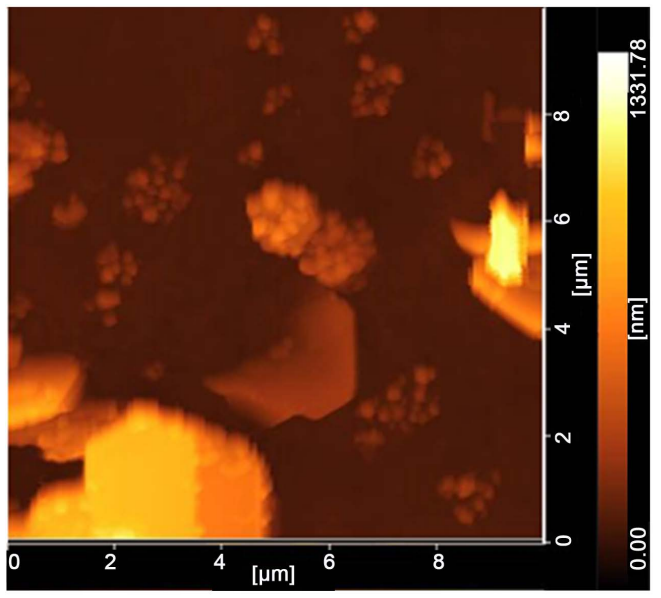

(a)

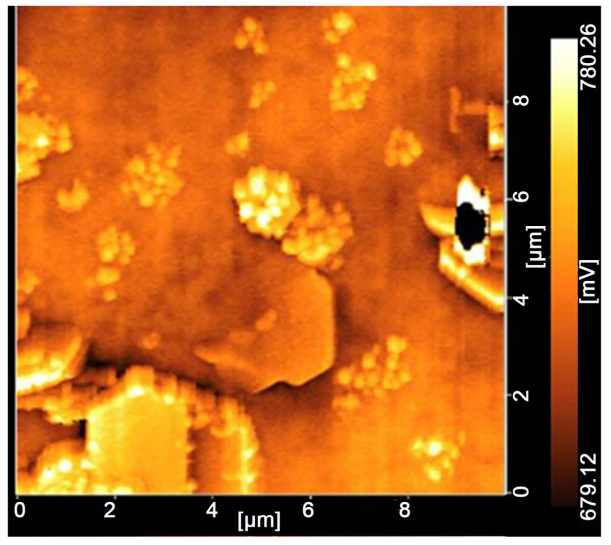

(b)

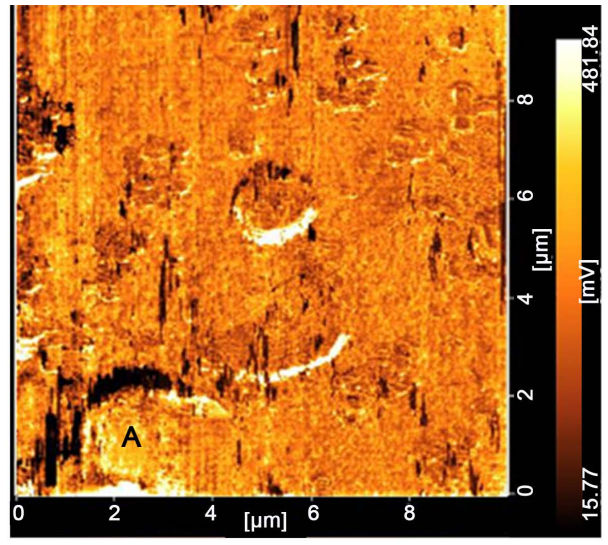

(c)

Figure 6. Surface properties of cement paste evaluated by SPM ( $24 \mathrm{~h}$ after acetone immersion). (a) Surface geometry; (b) Surface potential; (c) Frictional force. 


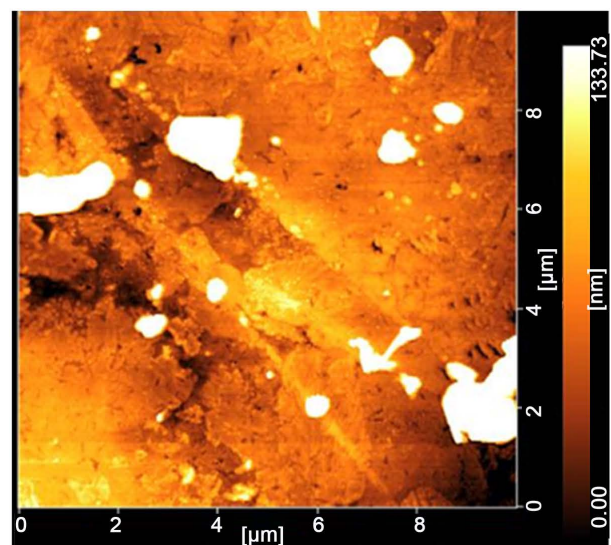

(a)

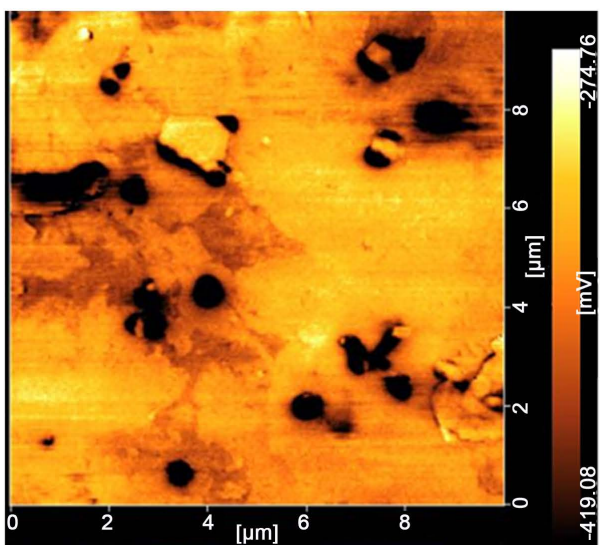

(b)

Figure 7. Surface properties of cement paste evaluated by SPM (1 month after acetone immersion). (a) Surface geometry; (b) Surface potential.

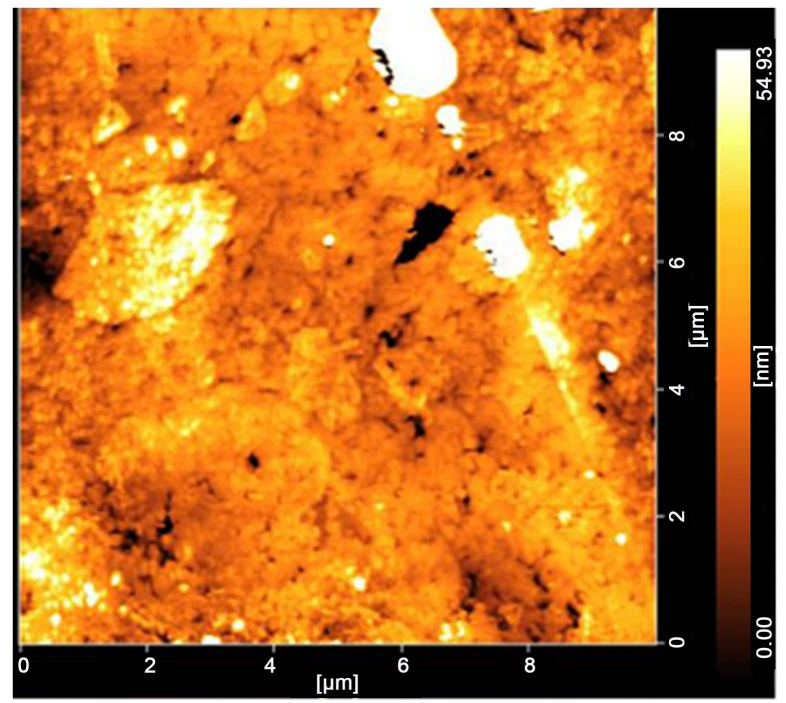

(a)

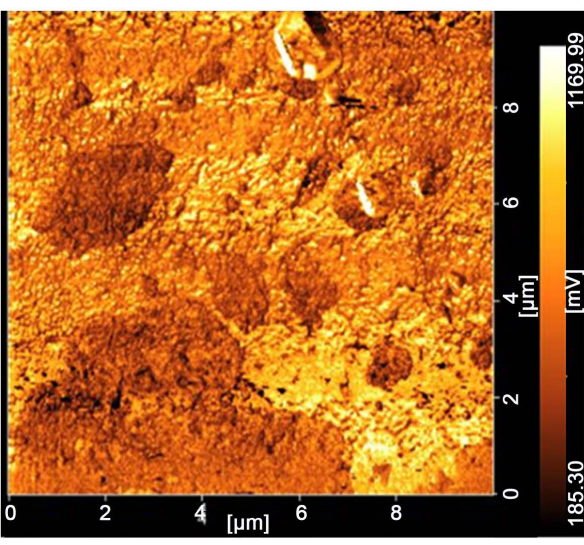

(b)

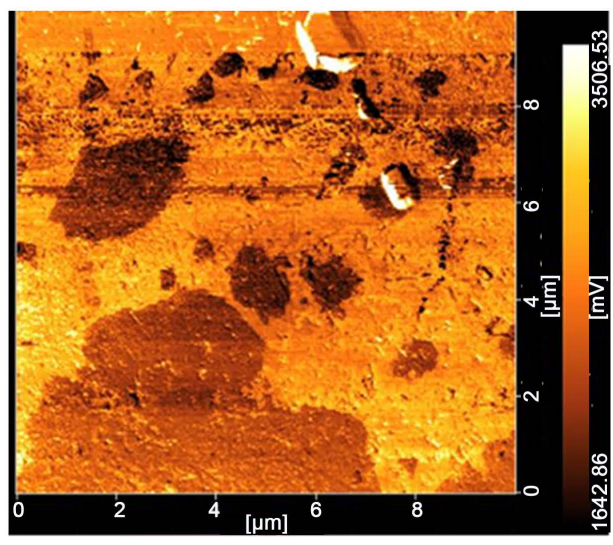

(c)

Figure 8. Surface properties of cement paste evaluated by SPM (1 month after preparation). (a) Surface geometry; (b) Surface potential; (c) Frictional force. 


\section{Discussion}

\subsection{SEM and FE-SEM/EDS}

SEM observation at the magnification of 7000 showed that the HCP surface was flat and had no holes. These results indicate that the dense HCPs with flat surfaces were prepared by curing under high pressure with a slide glass. High $\mathrm{Ca}$ and low Si signatures indicate that the hydrate $\mathrm{A}$ in Figure 3 and Figure 4 may be $\mathrm{Ca}(\mathrm{OH})_{2}$.

\subsection{Scanning Probe Microscopy}

The hydrates on the specimen, which was measured $24 \mathrm{~h}$ after the acetone immersion, exhibited a variation of surface properties along their edges, as seen in Figure 6(b) and Figure $6(\mathrm{c})$. This change in the surface properties is attributable to the differences in height but not to the actual variation of surface properties, because both properties are affected by the surface geometry. The surface potential and frictional force of the hydrates therefore may be similar over the measured area. The spots of low surface potential were observed on the sample that was tested one month after the acetone immersion. This result likely indicates an actual difference in surface potential because the change is not limited to the edges of the hydrates. Carbonation of hydrates might have caused the low surface potential areas, because the zeta potential of cementitious materials decreases significantly after carbonation [16]. Frictional force showed similar distribution over the measurement area $24 \mathrm{~h}$ after acetone immersion but there were less intense areas one month after the immersion, as shown in Figure 8. The hydrates generated by carbonation therefore likely had different frictional forces, compared to the other hydrates. The carbonated hydrates might have different viscoelasticity as well, as suggested by the low viscoelasticity areas in Figure 8, although the viscoelasticity was not measured $24 \mathrm{~h}$ after acetone immersion.

\section{Conclusions}

The conclusions obtained in this study are summarized as follows.

-The HCPs cured under $400 \mathrm{MPa}$ with a slide glass were dense and no holes or surface porosity were detected by SEM observation and SPM measurement.

-The hydrates had a similar surface potential and frictional force over the measured area when the HCP was measured $24 \mathrm{~h}$ after acetone immersion.

-The spots of low surface potential, low frictional force and low viscoelasticity were detected when the HCP was measured with SPM one month after acetone immersion. The change in these properties was attributed to the carbonation of hydrates.

\section{Acknowledgements}

This research was supported by a research grant from Japan Cement Association.

\section{References}

[1] Elakneswaran, Y., Nawa, T. and Kurumisawa, K. (2009) Influence of Surface Charge on In- 
gress of Chloride Ion in Hardened Pastes. Materials and Structures, 42, 83-93. http://dx.doi.org/10.1617/s11527-008-9368-8

[2] Elakneswaran, Y., Nawa, T. and Kurumisawa, K. (2009) Zeta Potential Study of Paste Blends with Slag. Cement and Concrete Composites, 31, 72-76. http://dx.doi.org/10.1016/j.cemconcomp.2008.09.007

[3] Kanazawa, T., Kikuchi, M., Saeki, T. and Saito, T. (2013) Effects of Zeta Potential on Diffusion of Chloride Ion in Hardened Cementitious Materials. Cement Science and Concrete Technology, 67, 378-385. http://dx.doi.org/10.14250/cement.67.378

[4] Bhushan, B. and Othmar, M. (2011) Scanning Probe Microscopy-Principle of Operation, Instrumentation, and Probes. In: Bhushan, B., Ed., Nanotribology and Nanomechanics I, Springer Berlin, Heidelberg, 37-110. http://dx.doi.org/10.1007/978-3-642-15283-2_2

[5] Chen, X.Q., Yamada, H., Horiuchi, T., Matsushige, K., Watanabe, S., Kawai, M. and Weiss, P.S. (1999) Surface Potential of Ferroelectric Thin Films Investigated by Scanning Probe Microscopy. Journal of Vacuum Science \& Technology B, 17, 1930-1934. http://dx.doi.org/10.1116/1.590851

[6] Zhang, L., Sakai, T., Sakuma, N., Ono, T. and Nakayama, K. (1999) Nanostructural Conductivity and Surface-Potential Study of Low-Field-Emission Carbon Films with Conductive Scanning Probe Microscopy. Applied Physics Letters, 75, 3527-3529. http://dx.doi.org/10.1063/1.125377

[7] Kalinin, S.V. and Bonnell, D.A. (2001) Temperature Dependence of Polarization and Charge Dynamics on the $\mathrm{BaTiO}_{3}$ (100) Surface by Scanning Probe Microscopy. Applied Physics Letters, 78, 1116-1118. http://dx.doi.org/10.1063/1.1348303

[8] Bhushan, B. and Goldade, A.V. (2000) Measurements and Analysis of Surface Potential Change during Wear of Single-Crystal Silicon (100) at Ultralow Loads Using Kelvin Probe Microscopy. Applied Surface Science, 157, 373-381. http://dx.doi.org/10.1016/S0169-4332(99)00553-X

[9] Chen, X., Yamada, H. and Matsushige, K. (1999) Investigation of Surface Potential of Ferroelectric Organic Molecules by Scanning Probe Microscopy. Japanese Journal of Applied Physics, 38, 3932. http://dx.doi.org/10.1143/JJAP.38.3932

[10] Lesko, S., Lesniewska, E., Nonat, A., Mutin, J.C. and Goudonnet, J.P. (2001) Investigation by Atomic Force Microscopy of Forces at the Origin of Cement Cohesion. Ultramicroscopy, 86, 11-21. http://dx.doi.org/10.1016/S0304-3991(00)00091-7

[11] Saez de Ibarra, Y., Gaitero, J. J., Erkizia, E. and Campillo, I. (2006) Atomic Force Microscopy and Nanoindentation of Cement Pastes with Nanotube Dispersions. Physica Status Solidi (a), 203, 1076-1081. http://dx.doi.org/10.1002/pssa.200566166

[12] Mondal, P., Shah, S.P. and Marks, L. (2007) A Reliable Technique to Determine the Local Mechanical Properties at the Nanoscale for Cementitious Materials. Cement and Concrete Research, 37, 1440-1444. http://dx.doi.org/10.1016/j.cemconres.2007.07.001

[13] Trtik, P., Kaufmann, J. and Volz, U. (2012) On the Use of Peak-Force Tapping Atomic Force Microscopy for Quantification of the Local Elastic Modulus in Hardened Cement Paste. Cement and Concrete Research, 42, 215-221. http://dx.doi.org/10.1016/j.cemconres.2011.08.009

[14] Sakai, Y., Nakatani, M., Takeuchi, A., Omorai, Y. and Kishi, T. (2016) Mechanical Behavior of Cement Paste and Alterations of Hydrates under High-Pressure Triaxial Testing. Journal of Advanced Concrete Technology, 14, 1-12. http://dx.doi.org/10.3151/jact.14.1

[15] Sakai, Y., Tarekegne, B.T. and Kishi, T. (2016) Recycling of Hardened Cementitious Material by Pressure and Control of Volumetric Change. Journal of Advanced Concrete 
Technology, 14, 47-54. http://dx.doi.org/10.3151/jact.14.47

[16] Andrade, C., Castellote, M., Sarría, J. and Alonso, C. (1999) Evolution of Pore Solution Chemistry, Electro-Osmosis and Rebar Corrosion Rate Induced by Realkalisation. Materials and Structures, 32, 427-436. http://dx.doi.org/10.1007/BF02482714

\section{Submit or recommend next manuscript to SCIRP and we will provide best service} for you:

Accepting pre-submission inquiries through Email, Facebook, LinkedIn, Twitter, etc.

A wide selection of journals (inclusive of 9 subjects, more than 200 journals)

Providing 24-hour high-quality service

User-friendly online submission system

Fair and swift peer-review system

Efficient typesetting and proofreading procedure

Display of the result of downloads and visits, as well as the number of cited articles

Maximum dissemination of your research work

Submit your manuscript at: http://papersubmission.scirp.org/

Or contact ojce@scirp.org 